\title{
Atomically Bonded Transparent Superhydrophobic Coatings
}

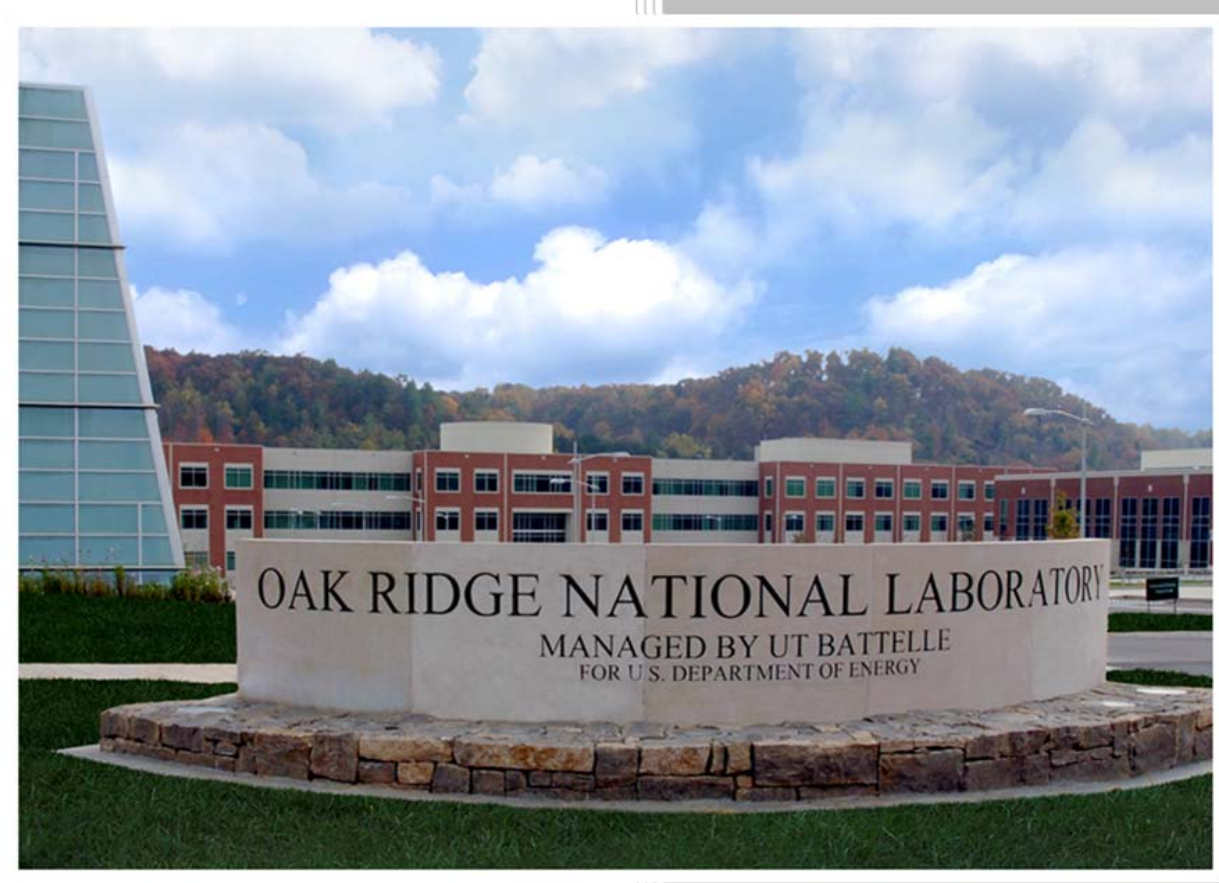

Approved for public release;

Tolga Aytug distribution is unlimited.

May 2015 


\section{DOCUMENT AVAILABILITY}

Reports produced after January 1, 1996, are generally available free via US Department of Energy (DOE) SciTech Connect.

Website http://www.osti.gov/scitech/

Reports produced before January 1, 1996, may be purchased by members of the public from the following source:

National Technical Information Service

5285 Port Royal Road

Springfield, VA 22161

Telephone 703-605-6000 (1-800-553-6847)

TDD 703-487-4639

Fax 703-605-6900

E-mail info@ntis.gov

Website http://www.ntis.gov/help/ordermethods.aspx

Reports are available to DOE employees, DOE contractors, Energy Technology Data Exchange representatives, and International Nuclear Information System representatives from the following source:

Office of Scientific and Technical Information

PO Box 62

Oak Ridge, TN 37831

Telephone 865-576-8401

Fax 865-576-5728

E-mail reports@osti.gov

Website http://www.osti.gov/contact.html

This report was prepared as an account of work sponsored by an agency of the United States Government. Neither the United States Government nor any agency thereof, nor any of their employees, makes any warranty, express or implied, or assumes any legal liability or responsibility for the accuracy, completeness, or usefulness of any information, apparatus, product, or process disclosed, or represents that its use would not infringe privately owned rights. Reference herein to any specific commercial product, process, or service by trade name, trademark, manufacturer, or otherwise, does not necessarily constitute or imply its endorsement, recommendation, or favoring by the United States Government or any agency thereof. The views and opinions of authors expressed herein do not necessarily state or reflect those of the United States Government or any agency thereof. 
Chemical Sciences Division

\title{
ATOMICALLY BONDED TRANSPARENT SUPERHYDROPHOBIC COATINGS
}

\author{
Tolga Aytug
}

Date Published: May 2015

Prepared by

OAK RIDGE NATIONAL LABORATORY

Oak Ridge, TN 37831-6283

managed by

UT-BATTELLE, LLC

for the

US DEPARTMENT OF ENERGY

under contract DE-AC05-00OR22725 



\section{CONTENTS}

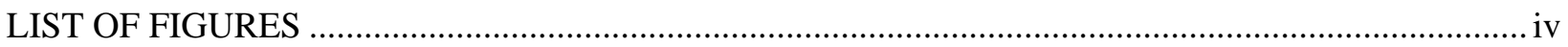

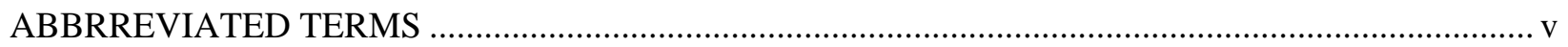

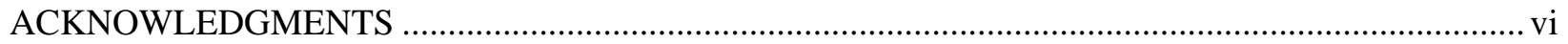

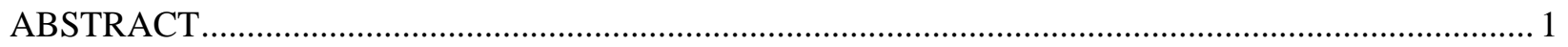

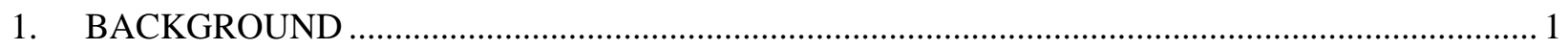

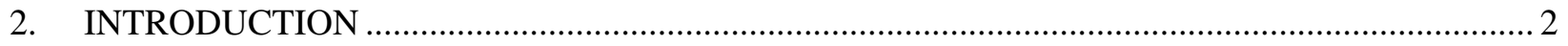

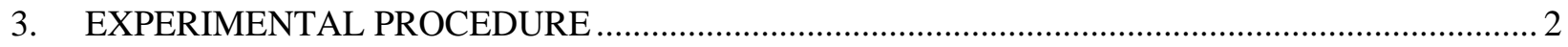

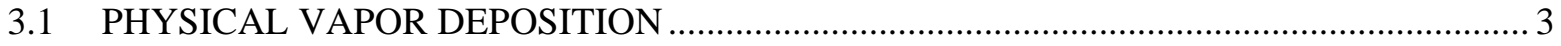

3.2 TRANSFORMATION OF THE AS-DEPOSITED FILMS TO NANOSTRUCTURED

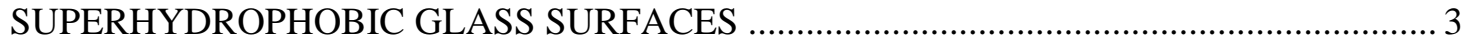

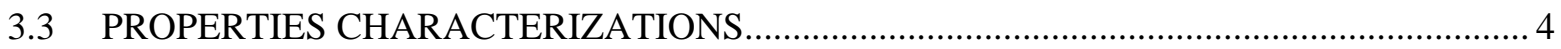

3.3.1 Water Droplet Contact Angle Measurements ............................................................. 4

3.3.2 Microstructural and Optical Characterization ............................................................ 5

3.3.3 Fracture Toughness and Abrasion Resistance Tests ..................................................... 5

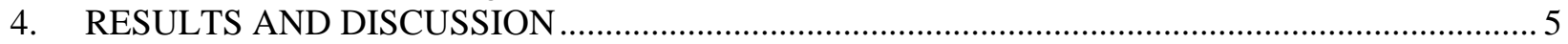

4.1 COMPOSITIONAL ANALYSIS OF THE FILMS AND IDENTIFICATION OF

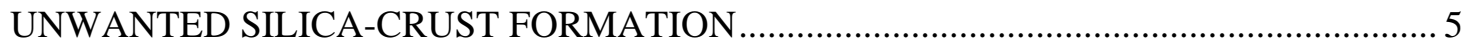

4.2 EFFORTS TO USE ULTRASONIC ACTIVATION DURING ETCHING TO MINIMIZE SILICA-CRUST FORMATION AND REMOVAL ........................................... 8

4.3 EFFORTS TO PRODUCE SPATIALLY UNIFORM REMOVAL OF THE SILICA

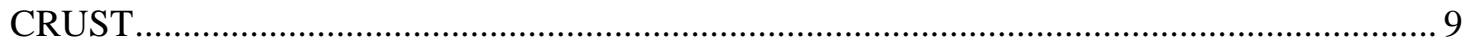

4.4 ACHIEVEMENT OF TRANSPARENT SUPERHYDROPHOBIC GLASS FILMS

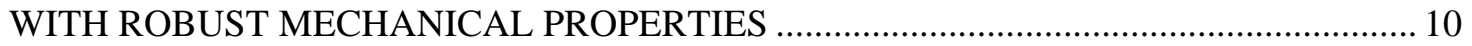

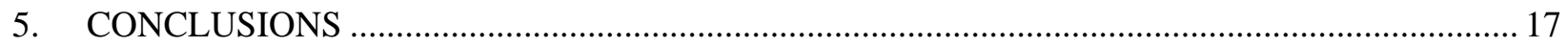

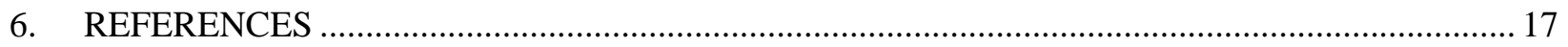




\section{LIST OF FIGURES}

Fig. 1. Thin glass film deposition procedure.

Fig. 2. Methods for creation of atomically bonded nanostructured superhydrophobic surfaces. ................. 4

Fig. 3. Comparison of atomic percentages of silicon ( $\mathrm{Si}$ ), sodium (Na), and boron (B) with respect to (a) deposition temperature during sputtering (samples heattreated for $30 \mathrm{~min}$ ) and (b) post thermal processing time (data is only shown for samples deposited at $400^{\circ} \mathrm{C}$ ).

Fig. 4. SEM image of a sputter-deposited phase-separating borosilicate thin film on a fusedquartz substrate, displaying the morphology of the surface after post thermal treatment................ 7

Fig. 5. Comparison of atomic percentages of Si, Na, and B for an as-deposited film and for the film after the post heat treatment.

Fig. 6. Optical microscope images illustrating evolution of the surface microstructure of sodium borosilicate thin films with respect to the etching process.

Fig. 7. Optical microscope images illustrating evolution of the surface microstructure of sodium borosilicate films processed using buffered oxide etch solution and ultrasonic enhancement for (a) $5 \mathrm{~min}$, (b) $7 \mathrm{~min}$, and (c) $10 \mathrm{~min}$.

Fig. 8. (a) Photograph of blue-dyed water droplets sitting on a superhydrophobic fused-quartz plate, displaying the transparency and superhydrophobic nature of the coating.

Fig. 9. SEM images illustrating (a) formation of spinodal two-phase separated structure after the heat treatment and (b) transformation of part (a) surface into a reticulated network nanostructure after the differential etching process.

Fig. 10. Photographs of a nanostructured thin-film-coated sample placed on an uncoated microscope slide (a) before and (b) after being subjected to fogging.

Fig. 11. (a) Optical transmittance spectra obtained through a nanostructured film surface........................ 13

Fig. 12. Scanning electron microscopy image of the $\mathrm{Al}_{2} \mathrm{O}_{3}$ particles used in the abrasion tests. ............... 14

Fig. 13. (a) Schematic of the setup used to evaluate mechanical stability and durability of the superhydrophobic silica film surface under simulated dust-storm conditions (highly abrasive $\mathrm{Al}_{2} \mathrm{O}_{3}$ particles were used).

Fig. 14. Atomic force microscopy images of cube-corner indentations obtained on an as-deposited and a nanotextured glass thin film.

Fig. 15. (a) Static contact angles of water droplets on a nanostructured superhydrophobic thin film, after successive 30 min exposures to the indicated temperatures. 


\section{ABBRREVIATED TERMS}

$\begin{array}{ll}\text { BES } & \text { US Department of Energy Basic Energy Sciences Program } \\ \text { BOE } & \begin{array}{l}\text { buffered oxide etchant } \\ \text { contact angle }\end{array} \\ \text { CA } & \text { Corrosion Prevention and Control } \\ \text { CPAC } & \text { US Department of Defense } \\ \text { DOD } & \text { US Department of Energy } \\ \text { DOE } & \text { energy-dispersive spectroscopy } \\ \text { EDS } & \text { National Oceanic and Atmospheric Administration } \\ \text { NOAA } & \text { US Marine Corps } \\ \text { USMC } & \text { Oak Ridge National Laboratory } \\ \text { ORNL } & \text { scanning electron microscopy } \\ \text { SEM } & \text { scanning transmission electron microscopy } \\ \text { STEM } & \text { ultraviolet } \\ \text { UV } & \text { atomic number }\end{array}$




\section{ACKNOWLEDGMENTS}

This work was supported in part by the Corrosion Prevention and Control (CPAC) Program of the US Marine Corps (Matt Koch, program manager) and in part by the Laboratory Directed Research and Development Technology Innovation Program of Oak Ridge National Laboratory (ORNL), managed by UT-Battelle, LLC, for the US Department of Energy (DOE). Scanning transmission electron microscopy research was supported by the DOE Basic Energy Sciences Program (BES) and performed in the Materials Sciences and Engineering Division. Mechanical property research was conducted at ORNL's High Temperature Material Laboratory, which is sponsored at ORNL by the Scientific User Facilities Division, Office of Energy Efficiency and Renewable Energy, US DOE. Other portions of this research were conducted at the Center for Nanophase Materials Sciences and Shared Research Equipment, which are sponsored at ORNL by the DOE BES Scientific User Facilities Division 


\begin{abstract}
Maintaining clarity and avoiding the accumulation of water and dirt on optically transparent surfaces such as US military vehicle windshields, viewports, periscope optical head windows, and electronic equipment cover glasses are critical to providing a high level of visibility, improved survivability, and much-needed safety for warfighters in the field. Through a combination of physical vapor deposition techniques and the exploitation of metastable phase separation in low-alkali borosilicate, a novel technology was developed for the fabrication of optically transparent, porous nanostructured silica thin film coatings that are strongly bonded to glass platforms. The nanotextured films, initially structurally superhydrophilic, exhibit superior superhydrophobicity, hence antisoiling ability, following a simple but robust modification in surface chemistry. The surfaces yield water droplet contact angles as high as $172^{\circ}$. Moreover, the nanostructured nature of these coatings provides increased light scattering in the UV regime and reduced reflectivity (i.e., enhanced transmission) over a broad range of the visible spectrum. In addition to these functionalities, the coatings exhibit superior mechanical resistance to abrasion and are thermally stable to temperatures approaching $500^{\circ} \mathrm{C}$. The overall process technology relies on industry standard equipment and inherently scalable manufacturing processes and demands only nontoxic, naturally abundant, and inexpensive base materials. Such coatings, applied to the optical components of current and future combat equipment and military vehicles will provide a significant strategic advantage for warfighters. The inherent self-cleaning properties of such superhydrophobic coatings will also mitigate biofouling of optical windows exposed to high-humidity conditions and can help decrease repair/replacement costs, reduce maintenance, and increase readiness by limiting equipment downtime.
\end{abstract}

\title{
1. BACKGROUND
}

Highly nonwetting natural biological surfaces (e.g., lotus leaves and water strider legs) have inspired strategies for the synthesis of artificial superhydrophobic surfaces that exhibit water droplet contact angles (CAs) exceeding 150 . [1-3]. Such bio-inspired, water-repellent surfaces offer significant potential for numerous uses, ranging from marine applications (e.g., antibiofouling, anticorrosion), anticondensation (e.g., antiicing, antifogging), membranes for selective separation (e.g., oil-water, gasliquid), microfluidic systems, and surfaces requiring reduced maintenance and cleaning to applications involving glasses and optical materials [4]. For integration into commercial systems/applications that have extended operational limits and overall improved performance, surfaces that also possess multifunctional characteristics are desired, where the functionality should match the application-specific requirements. In particular, to realize the full potential for the optical and glass-based applications, surfaces might require antireflective and antifogging functionalities in addition to being mechanically robust and optically transparent [5-8]. Implicit to achieving these properties is the equally important requirement that such surfaces be produced by commercially viable manufacturing processes. To date it has been very challenging to obtain a transparent superhydrophobic medium while maintaining high optical quality and mechanical durability [9-11], mainly because the surface features necessary for hydrophobicity may lead to severe light scattering, which renders surfaces nearly opaque or translucent; moreover, surfaces with large roughness usually exhibit weak mechanical stability [12-14].

It is well known that the combined effects of appropriate surface roughness and low surface energy (i.e., surface chemistry) are responsible for superhydrophobicity $[1,15,16]$. An optimal rough surface morphology creates a composite air-solid interface by trapping small-scale air pockets within the film, leading to greatly reduced contact area between solid and liquid droplet, which enhances the hydrophobic properties through reduced van der Waals forces. Although superhydrophobic transparent coatings have been reported in the literature [17], the films are mostly based on roughened or porous polymers [18-20], sol-gel [21,22] and spray-on coatings [23-25], assembly of nanoarrays or nanostructures onto surfaces [26-29], and lithographic methods or template-assisted techniques [1]. Such coatings must be frequently 
reapplied and are not suitable for military applications [2]. The polymer-based films are typically poorly bonded to the substrate and thus are not sufficiently durable to satisfy most application requirements [12,30,31]. In addition, the associated harsh chemical preparation procedures (i.e., use of chemical solvent mixtures) tend to degrade the physical properties of the underlying materials. Similarly, powder-based coatings exhibit poor durability due to the application-specific polymer-based binding agents. Sol-gel based coatings have a propensity for better bonding, but they generally exhibit poor hydrophobic qualities (low water CA) due to the lack of nanoscale sharpening and porosity [26,32,33]. Coatings based on nanoarrays or nanoparticles and lithographic techniques possess similar problems as polymer or sol-gel based films [13]. Furthermore, fabrication of nanostructure assemblies involves elaborate processing schemes, and in many cases the toxicity of the different reagents used in the processes poses risks to human health and concerns for the environment [26] that render them unsuitable for large-scale development and production [4].

Many of these common problems have been overcome by combining physical vapor deposition techniques (i.e., magnetron sputtering) with exploitation of metastable phase separation in low-alkali borosilicate glasses to produce differentially etched, nanostructured glass materials. The fabrication methods developed through this research rely on industry standard equipment and scalable manufacturing processes and utilize materials that are nontoxic, naturally abundant, and inexpensive.

This research is part of an overall larger effort and fits well into the strategic focus of the US Marine Corps (USMC) Corrosion Prevention and Control (CPAC) program at Oak Ridge National Laboratory (ORNL). The technology developed within the CPAC program has the potential to significantly enhance the functionality and performance of the combat vehicles and equipment that are exposed to wet and harsh environments by shedding water/moisture from the surface while providing optical clarity.

The combination of the robustness of the coating and its advanced functionality has the potential to have a huge effect in general for optical components used by all of the organizations that are under the purview of US Department of Defense (DOD). This unique technology will provide a much-needed improvement in safety, increased readiness, and an overall strategic advantage to US warfighters. In addition, the inherent self-cleaning properties of such coatings will also mitigate biofouling of optical windows used in military assets.

\section{INTRODUCTION}

The goal of this research was to achieve a technological leap that will enable large-area, durable superhydrophobic coatings to be applied to optically transparent surfaces of materials (glass in this case) that are not compromised by the needed $\sim 600^{\circ} \mathrm{C}$ processing of the superhydrophobic coating. The proposed techniques have been identified as new developmental opportunities for military applications. The strategies examined in this research seek to overcome the problems encountered in earlier work and are aimed to achieve very high levels of mechanical, thermal and environmental stability for superhydrophobic coatings that can be applied to optical windows on USMC vehicles and selected equipment. Because the nanoscale surface features are smaller than the wavelengths found in visible light, the coatings are expected to be intrinsically antireflective over the visible light spectrum, providing additional functionality.

\section{EXPERIMENTAL PROCEDURE}

This research combines physical vapor deposition techniques to fabricate extremely uniform thin film coatings with novel methods to produce differentially etched, superhydrophobic surface-structured materials. 


\subsection{PHYSICAL VAPOR DEPOSITION}

Physical vapor deposition processing, in particular magnetron sputtering, has been used to demonstrate the formation of uniform and strongly adhered thin films (100-500 nm thick) of an ORNL-specific sodium borosilicate glass onto fused-quartz substrates. The sputtering technique is attractive because multicomponent materials such as alloys or compounds at stoichiometric compositions can be easily deposited and because sputter coating of plate glass surfaces is a well-known industrial coating method. In addition, since sputtered species arrive at the substrate with high kinetic energy and with various angles of incidence; highly dense films with exceptional coverage can be obtained, even on irregular surfaces. Furthermore, sputtering techniques can easily be adapted for complex, continuous, and large-area depositions, which offer a unique advantage for the potential use to fabricate such coatings for a wide range of applications.

Thin-film coatings were deposited on a 2 in. sputtering target of borosilicate glass (composition 66 mole $\% \mathrm{SiO}_{2}, 26$ mole $\% \mathrm{~B}_{2} \mathrm{O}_{3}$, and 8 mole $\% \mathrm{Na}_{2} \mathrm{O}$ ) (Fig. 1). The stoichiometry of the deposited films was carried out using energy-dispersive spectroscopy (EDS). Optical microscopy and scanning electron microscopy (SEM) were employed to identify the surface microstructure, particularly surface roughness and uniformity, of the deposited coatings.

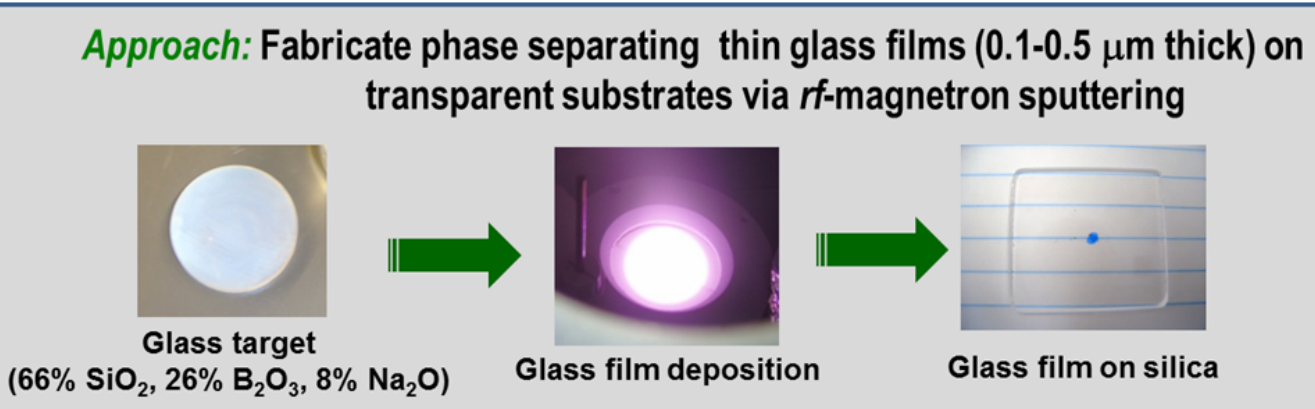

Fig. 1. Thin glass film deposition procedure.

\subsection{TRANSFORMATION OF THE AS-DEPOSITED FILMS TO NANOSTRUCTURED SUPERHYDROPHOBIC GLASS SURFACES}

The conversion to a superhydrophobic surface is a vital component of the methodology because it enables postdeposition transformation of the phase-separating coating into a completely adhered, transparent, and superhydrophobic thin glass film that possesses the additional functionality of visible-light antireflectivity. The conversion process can produce nanostructured materials or templates with the precise control of surface features that is required to produce both superhydrophobicity and transparency. The basic approach to make such films is to begin with phase-separating glass that is capable of spinodally decomposing (i.e., nonnucleation, continuous phase) when properly thermally processed. The phase-separated, structurally connected features scatter light due to the slight differences in the phase's refractive indices. This light scattering is wavelength dependent and is known as Rayleigh scattering. Once the coating has been applied and phase-separated (typically by heat treating) into a spinodal pattern, a controlled level of differential etching is required to completely remove one phase and to partially remove another phase of the spinodal structure. The resulting surface structure has a very porous, reticulated network with an extremely small "funnel cake" or "coral” appearance.

The final step is to covalently bond a chemically hydrophobic self-assembled-monolayer (SAM) to the etched surface; the SAM transforms the nanostructured glass surface from hydrophilic to superhydrophobic. To be optically transparent, the underlying structure should have a texture with 
features that are smaller than the smallest wavelengths found in visible light $(<400 \mathrm{~nm})$. The dimensions of the desired spinodal features can be controlled by adjusting the processing parameters. Moreover, because the coating and substrate are inherently similar (virtually identical if the substrate is amorphous silica), intimately bonded materials, the resulting entity is essentially monolithic, providing advancements of both fundamental and practical significance.

More specifically, after the deposition, the surface coating is heat-treated for at least 15 to 20 min at temperatures ranging from $600^{\circ} \mathrm{C}$ to $710^{\circ} \mathrm{C}$ to produce adequate spinodal decomposition. The temperature range and the hold time are regulated based on the glass substrate material. However, a phase-separated spinodal structure is not by itself sufficient to create superhydrophobic behavior. Therefore, the heattreated surface structure is etched with a 1:5 dilute mixture of buffered oxide etchant (BOE), (i.e., a mixture of ammonium fluoride and hydrofluoric acid) and deionized water to establish the correct volume fraction for a high-quality superhydrophobic structure. The etchant creates a nanoscale branched network by differentially eradicating all the sodium borate phase, leaving the silica-rich phase protruding from the surface. The final thickness of the film's etched-out portion is adjusted through a combination of deposition time and variable etch parameters. To create the superhydrophobic functionality, the etched samples are immersed in a mixture of hexane and $0.5 \mathrm{vol} \% 1 \mathrm{H} ; 1 \mathrm{H} ; 2 \mathrm{H} ; 2 \mathrm{H}$-perfluorooctyltrichlorosilane (Gelest, Inc., 95\%) for $30 \mathrm{~min}$ and then annealed in an oven at $115^{\circ} \mathrm{C}$ for $15 \mathrm{~min}$. The processing steps are summarized in Fig. 2.

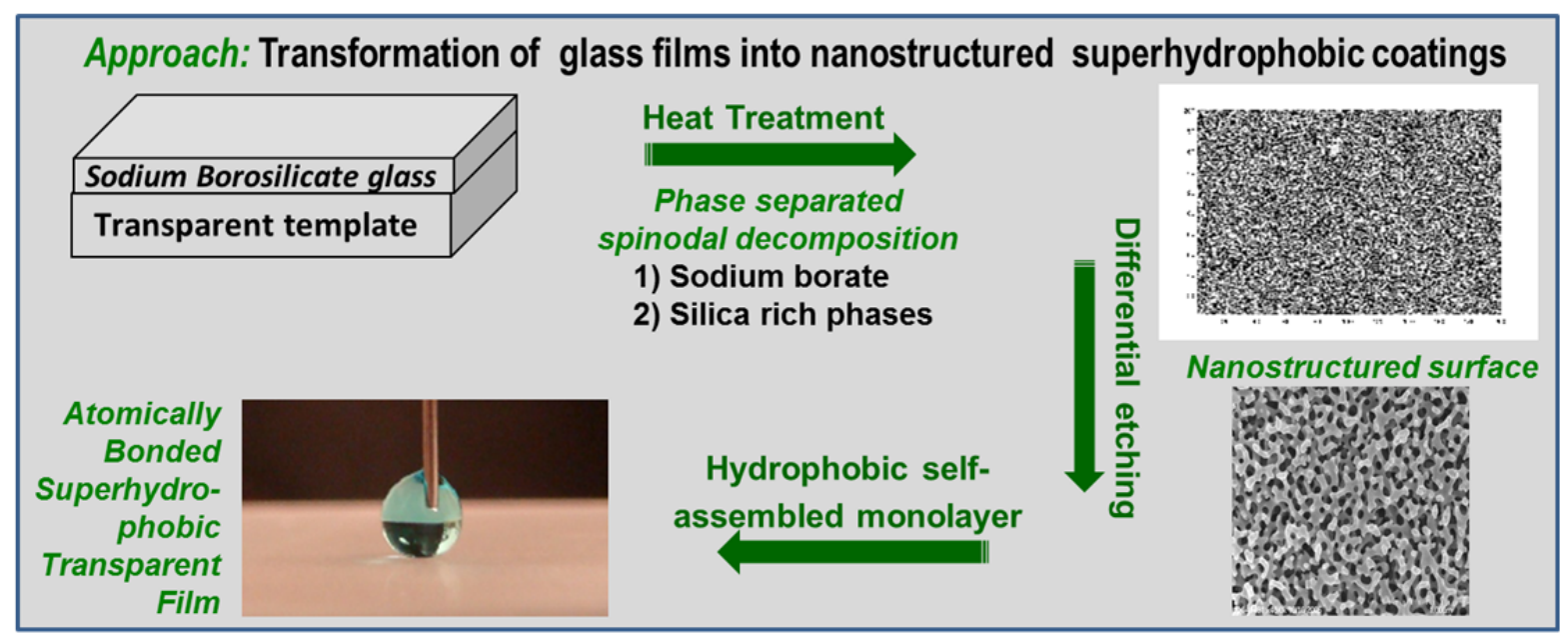

Fig. 2. Methods for creation of atomically bonded nanostructured superhydrophobic surfaces.

\subsection{PROPERTIES CHARACTERIZATIONS}

\subsubsection{Water Droplet Contact Angle Measurements}

Static, advancing (i.e., downhill angle), and receding (i.e., uphill angle) contact angle measurements were performed using an Attension Theta model T301 optical tensiometer (Biolin Scientific, Finland). Static contact angles were determined by taking the average of at least ten $6 \mu \mathrm{L}$ distilled water droplets dispensed at different positions on the film. The advancing and receding angles were measured by sessile drop experiments; values were determined automatically during the growth and shrinkage of the droplet. Roll-off angles were established by using a manual tilting stage. 


\subsubsection{Microstructural and Optical Characterization}

Plane-view surface morphology of the nanostructured films was examined using a Hitachi S-4100 highresolution field-emission type SEM. Cross sectional microstructures were studied by Z-contrast scanning transmission electron microscopy (STEM). The Z-contrast images are sensitive to the atomic species through the atomic number $(Z)$. Cross-sectional STEM specimens were prepared by focused ion beam milling, and the images were recorded on a Nion UltraSTEM operating at $200 \mathrm{kV}$. Surface morphology studies were performed on a VK-9700 3D laser scanning confocal microscope equipped with a $0.9 \mathrm{nW}$ $408 \mathrm{~nm}$ laser, and optical transmittance measurements were carried out using a Cary $5000 \mathrm{UV}$-visible light-near-infrared spectrophotometer. Angle-dependent measurements were taken by rotating the specimen, where the measured angle was between the direction of the incident light and the surface normal. ng A Perkin-Elmer Lambda 900 spectrophotometer with two $6^{\circ}$ relative reflectance attachments was used to measure the reflectance of the samples.

\subsubsection{Fracture Toughness and Abrasion Resistance Tests}

Coating indentation fracture resistance was evaluated by nanoindentation measurements using a Hysitron Triboindenter (Minneapolis, Minnesota) on films that were approximately $1 \mu \mathrm{m}$ in thickness.

Nanoindentation is a widely accepted tool for measuring the mechanical properties of thin films and small volumes of material. Although it is not an ideal test method to measure indentation fracture resistance, due to the reliance on plastic deformation of the material, nanoindentation provides information about the energy required to create and propagate a crack on the film. Measurements were performed on both asdeposited films (before the heat treatment and differential etching steps) and on the final etched product using a cube-corner indenter with a $100 \mathrm{~nm}$ tip radius (the cube-corner indenter was chosen due to high stress imposed in the vicinity of the contact area). Measurements were made at different loads up to the equipment`s maximum load of $10,500 \mu \mathrm{N}$, and the indented impressions were imaged by using the nanoindenter's tip to provide topographical images similar to those obtained using atomic force microscopy. The penetration depth at each load was documented to determine how close the indenter tip was to the film's interface with the substrate.

Two methodologies were invoked for the abrasion tests. The first method involved impingement of $100 \mathrm{~g}$ of commercial $\mathrm{Al}_{2} \mathrm{O}_{3}$ particles (irregular shapes with dimensions ranging from 100 to $300 \mu \mathrm{m}$ ) onto a superhydrophobic surface from a height of $35 \mathrm{~cm}$ while the sample was positioned at $45^{\circ}$ to the horizontal surface. $\mathrm{Al}_{2} \mathrm{O}_{3}$ is widely used as an abrasive medium owing to its high hardness ( 9 on the Mohs scale of mineral hardness) and strength. In the second method, $\mathrm{Al}_{2} \mathrm{O}_{3}$ particles were impacted normal to the same superhydrophobic surface at a velocity of 40 to $80 \mathrm{~km} \mathrm{~h}^{-1}$ for $15 \mathrm{~min}$. The velocity of $\mathrm{Al}_{2} \mathrm{O}_{3}$ particles was determined from wind speed measurements using a hot wire anemometer (General Tools model CIH20DL).

\section{RESULTS AND DISCUSSION}

\subsection{COMPOSITIONAL ANALYSIS OF THE FILMS AND IDENTIFICATION OF UNWANTED SILICA-CRUST FORMATION}

Special attention was paid to the composition and surface condition of the resulting film because a thin layer of $\mathrm{SiO}_{2}$ (termed "silica-crust") consistently formed on the sample surfaces after the heat treatment step. Hence it was very important to understand the factors that caused the crust formation as well as to correlate the influence of sputter deposition temperature, sputter gas composition, and post-deposition heat-treatment time with the microstructure and composition of the films. Screening of the stoichiometry was carried out using EDS. The results showed systematic differences in composition of the films with 
respect to the deposition temperature and heat treatment duration [Figs. 3(a) and (b)]. It is clear that while the Na signal remains relatively unchanged, Fig. 3 reveals reduced B and enhanced Si yields with respect to both increase in deposition temperature and heat treatment duration. In particular, a significant change in composition even after 30 min post-deposition thermal processing is evident from the Fig. 3(b). The change in composition clearly indicates silica-crust formation on the sample surfaces. That finding was corroborated by SEM imaging (Fig. 4) and compositional analysis (data not shown here). This behavior is not surprising considering the high volatility of B at elevated temperatures.

Films were deposited on another set of samples in an effort to understand the influence of the gas environment on the crust formation. Deposition was carried at room temperature $\left(\sim 25^{\circ} \mathrm{C}\right)$ and under $\mathrm{Ar}$ and/or a mixture of $\mathrm{Ar} / \mathrm{O}_{2}$ in order. Clearly, after the post-deposition thermal processing at $700^{\circ} \mathrm{C}$, Si crust formation is also evident from the Fig. 5, which agrees well with the observations obtained from Figs. 3(a) and (b).
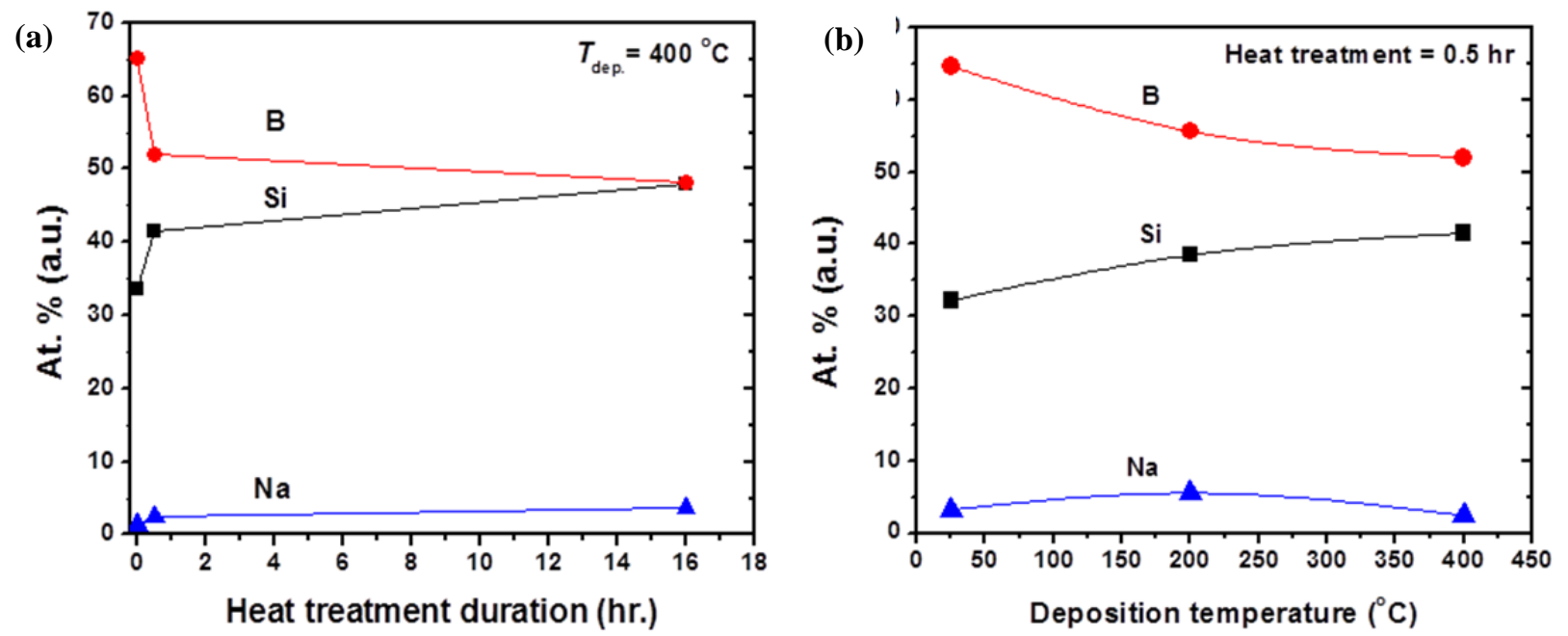

Fig. 3. Comparison of atomic percentages of silicon (Si), sodium (Na), and boron (B) with respect to (a) deposition temperature during sputtering (samples heat-treated for $30 \mathrm{~min}$ ) and (b) post-deposition thermal processing time (data is only shown for samples deposited at $\mathbf{4 0 0}^{\circ} \mathrm{C}$ ). For this set, samples were heattreated at $710^{\circ} \mathrm{C}$. All films have similar thicknesses, around $1 \mu \mathrm{m}$. 


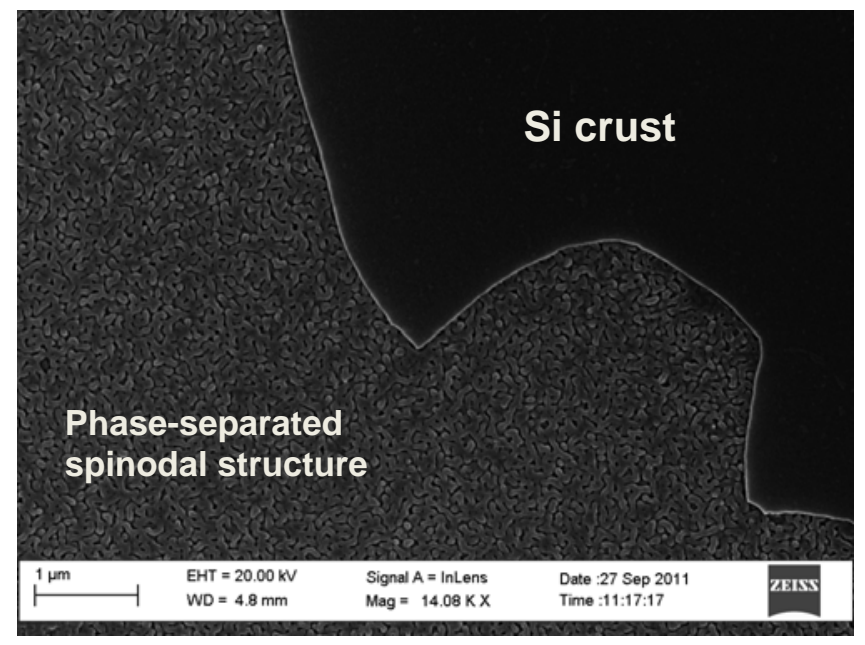

Fig. 4. SEM image of a sputter-deposited phase-separating borosilicate thin film on a fused-quartz substrate, displaying the morphology of the surface after post-deposition thermal treatment. Regions of silica crust along with underlying spinodal film structure are visible on the sample surface.

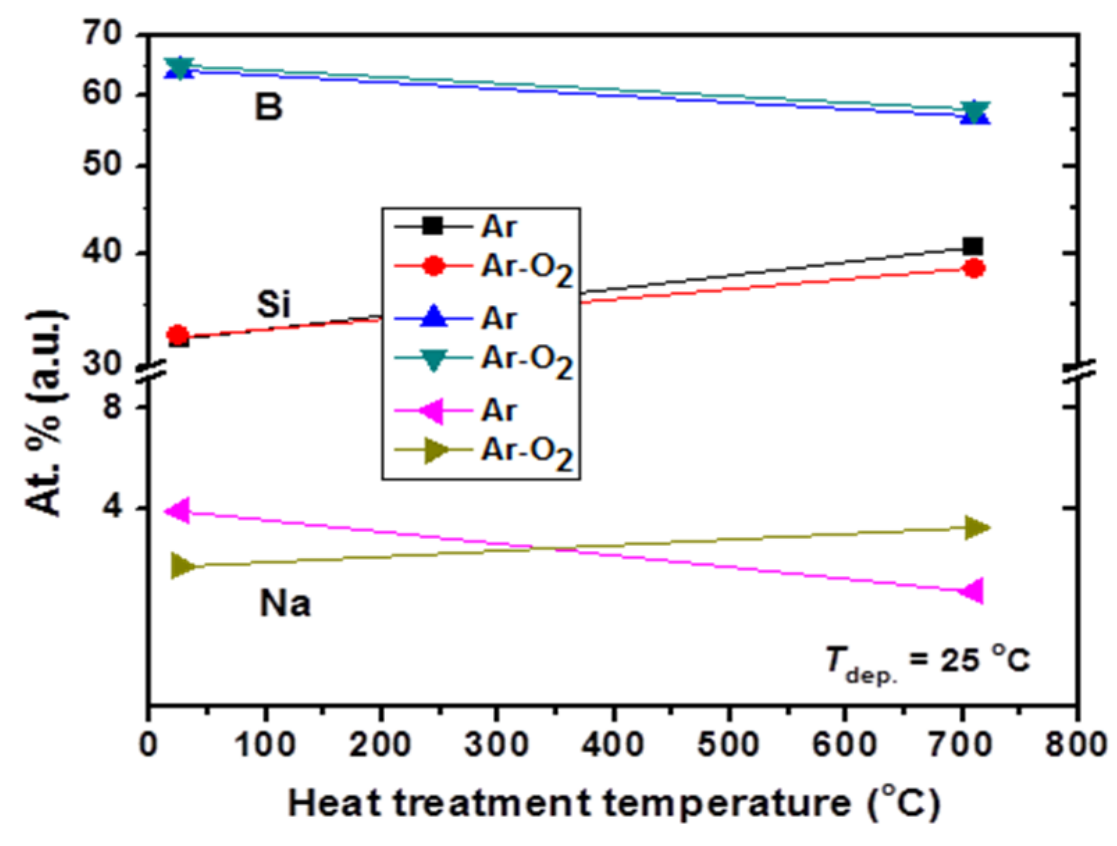

Fig. 5. Comparison of atomic percentages of $\mathrm{Si}, \mathrm{Na}$, and $\mathrm{B}$ for an as-deposited film and for the film after the post-deposition heat treatment. All the films in this group were deposited at $25^{\circ} \mathrm{C}$ under $\mathrm{Ar}$ and $\mathrm{Ar}-\mathrm{O}_{2}$ atmosphere and thermally processed at $710^{\circ} \mathrm{C}$ for $30 \mathrm{~min}$.

However, the slightly reduced Si and increased Na yields (after the post-deposition heat treatment) for the oxygen-processed films suggest that $\mathrm{Na}$ and $\mathrm{Si}$ are more strongly bonded in the samples and they form stoichiometric films. Observations presented in Figs. 3 and 5 are particularly important, indicating the possibility of minimizing the formation of silica crust by adjusting the processing parameters during the film growth. 


\subsection{EFFORTS TO USE ULTRASONIC ACTIVATION DURING ETCHING TO MINIMIZE SILICA-CRUST FORMATION AND REMOVAL}

During differential etching, samples were immersed in a dilute HF solution ( $0.5 \mathrm{vol} \%)$ bath to remove the silica crust. The rate of chemical reaction was accelerated via ultrasonic activation. Optical microscopy images (Fig. 6) show evolution of sample surface morphology with respect to the etching sequence. For comparison, an image of the as-deposited sample surface after thermal processing (but before etching treatment) is displayed in Fig. 6a, revealing smooth and uniform coverage of the surface by the Si-rich crust. Figures 6(b) and (c) show changes of the surface features during etching. These images reveal that the silica crust can be etched away rather easily by employing ultrasonic activation [Fig. 6(c)], compared to the case where the film is only soaked in an acid bath [Fig. 6(b)] without any activation. The image presented in Fig. 6(c) is of the same film surface as that shown in Fig. 6(b) after being soaked in the acid bath and after being exposed to an additional ultrasonic treatment. The circular pockets in the images of Fig. 6, which represent the etched-out regions in the film, appear as raised areas or plateaus because an inverted microscope (i.e., a microscope in which light comes from above the sample stage and the lens system is below the stage) was used to obtain the images. The hill-like smooth circular plateaus in the image are the regions that are completely etched out (all the way down to the glass substrate); the rougher regions denote the areas where etchant has dissolved the silicon crust, revealing the desired nanostructured surface features.

Despite the development of surface nanostructure with prolonged HF exposure, the sizes of the completely etched-out film regions also increase [Fig. 6(c)]. Figure 6(d) displays the surface morphology of the region (by SEM) surrounding the nanostructured features where in some areas the etching process is almost complete (i.e., the film is completely etched out) and in other areas a very porous nanostructured network is clearly evident. This observation is important because superhydrophobic behavior is dependent on the volume fraction and basic nature of the etched spinodal surface structure. Hence, to achieve superhydrophobic attributes in the films, the influences of etchant type, concentration, and etch time need be clearly understood and defined. Such parameters will have to be controlled and optimized to eventually obtain the ideal surface microstructures over a large area of glass surface, such as a windshield or a viewport. 

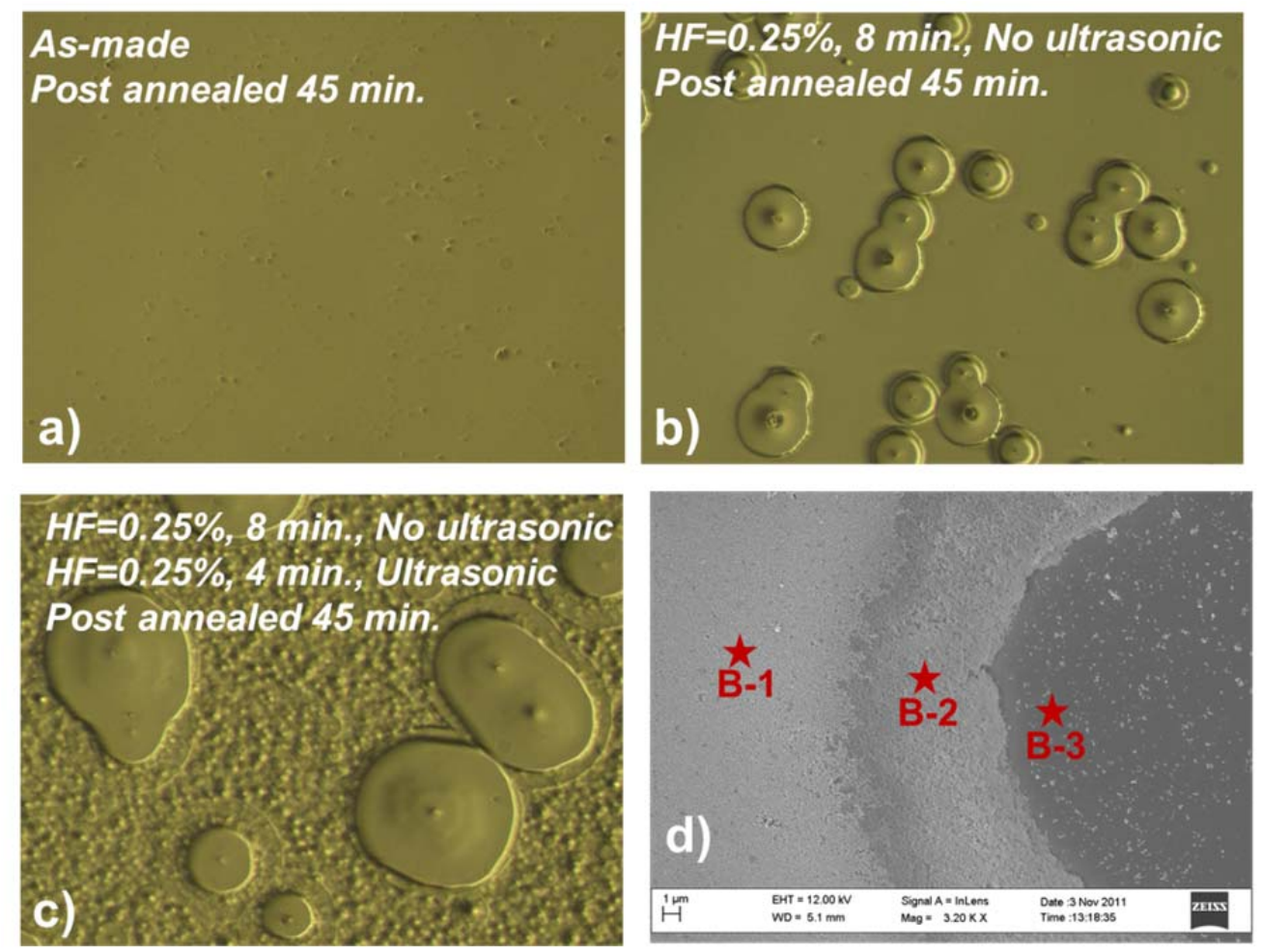

Fig. 6. Optical microscope images illustrating evolution of the surface microstructure of sodium borosilicate thin films with respect to the etching process. (a) Before etch treatment. (b) Sample without ultrasonic activation and (c) followed by ultrasonic activation [same film shown in (b)] of the etchant (etch conditions were displayed on the images). All optical images have the same magnification. (d) SEM image of a representative region of the surface where the film is gradually dissolved (sections denoted by B-1 and B-2) and completely etched out (B-3), exposing the underlying substrate.

\subsection{EFFORTS TO PRODUCE SPATIALLY UNIFORM REMOVAL OF THE SILICA CRUST}

Due to the difficulties with over-etching encountered with the dilute HF solution(see Sect. 4.2), a BOE solution (hydrofluoric acid mixed with $\mathrm{NH}_{4} \mathrm{~F}$ as a buffering agent) was used to slow down the reaction and to provide an anisotropic chemical etch evolution for the films. BOE was employed to provide a controlled etching process for the sputtered sodium borosilicate glass films. The diluted HF solution has proven to be aggressive and resulted in overly rapid and often uncontrollable etching of the top silica crust as well as the underlying film matrix [Fig 6(b) and (c)]. Clearly such films exhibited inhomogeneous removal of the crust and hence inconsistent etching of the film matrix in various regions. By comparison, films etched with BOE at various times displayed homogeneous and controllable etch evolution and spatially uniform surface microstructures [Figs. 7(a-c)]. Figures 7(b) and (c) show uniform etch evolution, but it is also clear that the surface features disappear during extended etch times. Nevertheless, compared to isotropic etching using pure HF solution, BOE facilitates an anisotropic etching process where inward etching proceeds more quickly than the lateral etching, providing uniform removal of the silica crust and increased etch control to achieve the surface microstructure that enables superhydrophobic behavior. This is a significant breakthrough in processing. It enables reproducible fabrication of coatings on various glass substrate materials. 


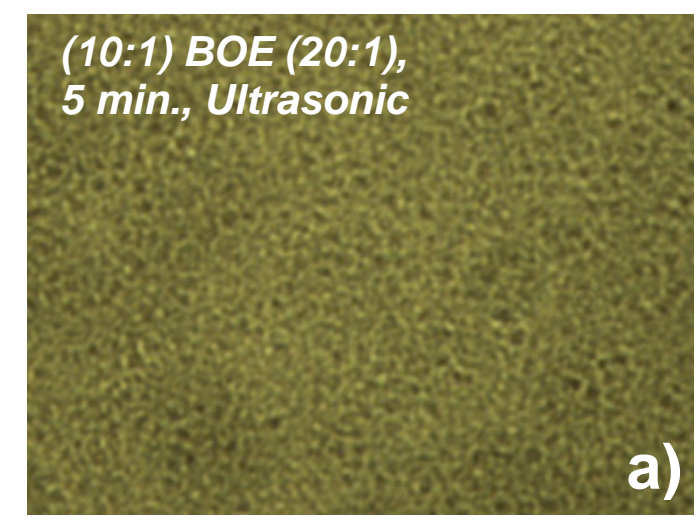

\section{(10:1) BOE (20:1), \\ 7 min., Ultrasonic}

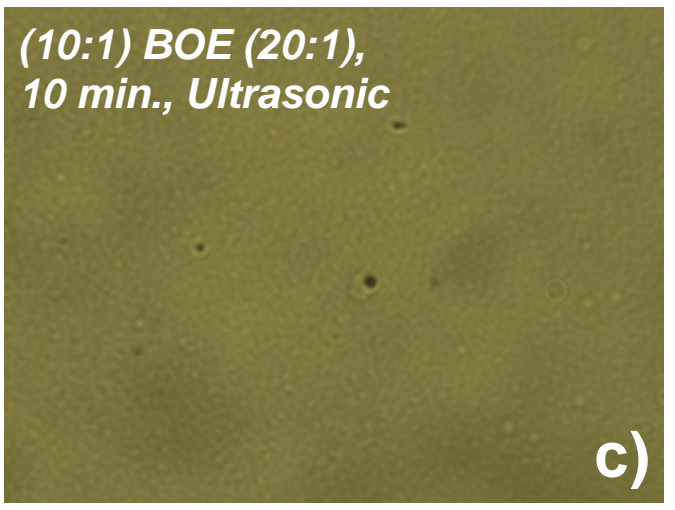

Fig. 7. Optical microscope images illustrating evolution of the surface microstructure of sodium borosilicate films processed using buffered oxide etch solution and ultrasonic enhancement for (a) 5 min, (b) 7 min, and (c) $10 \mathrm{~min}$. Etch conditions are displayed on the images. All images have the same magnification.

\subsection{ACHIEVEMENT OF TRANSPARENT SUPERHYDROPHOBIC GLASS FILMS WITH ROBUST MECHANICAL PROPERTIES}

Following progress in developing parameters for deposition and etching of the thin films, a transparent superhydrophobic thin film coating was produced on a fused-quartz substrate slide. Figure 8(a) displays a photograph of an atomically bonded, transparent superhydrophobic coating on a fused-quartz substrate, revealing superhydrophobic characteristics and excellent transparency of the coating. The surface morphologies of this sample, before and after the etching step, are displayed in Figs. 9(a) and (b). Following heat treatment, an ideal, thermally induced, spinodally decomposed phase-separated structure (i.e., a structurally connected continuous phase) was observed (Fig. 9a). The etching process produced the surface morphology desired for high-quality superhydrophobic performance (a porous, reticulated network with extremely small feature size, resembling a funnel cake or coral) [Fig. 9(b)]. 

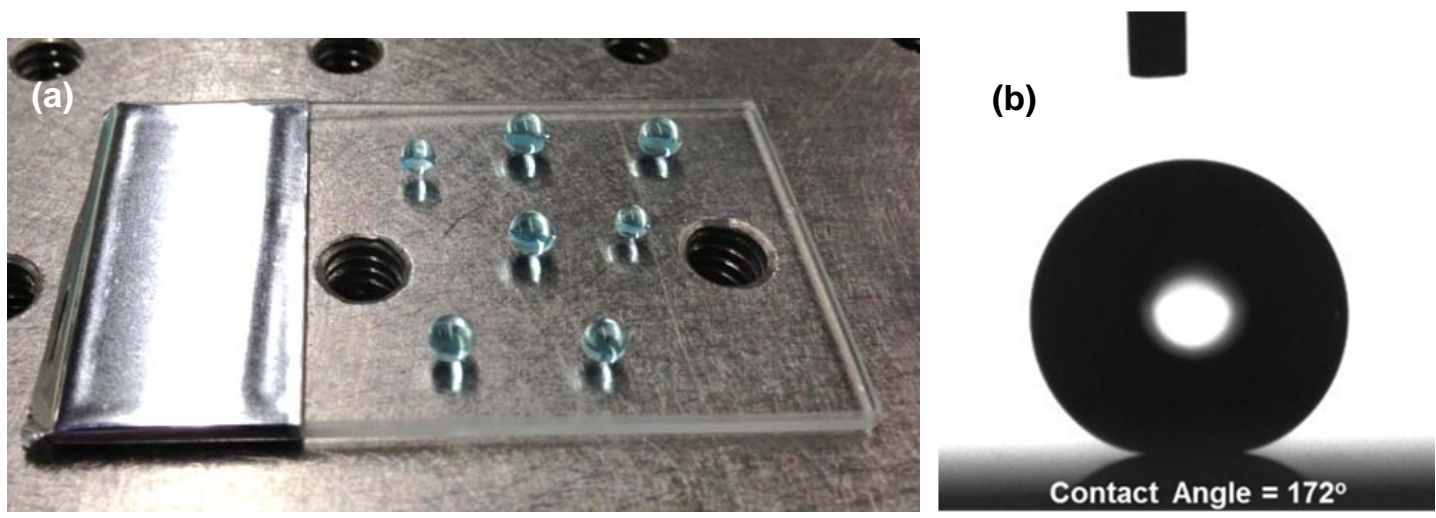

Fig. 8. (a) Photograph of blue-dyed water droplets sitting on a superhydrophobic fused-quartz plate, displaying the transparency and superhydrophobic nature of the coating. (b) The profile of a $6 \mu \mathrm{L}$ water droplet placed on a similarly nanostructured film, showing a static contact angle of $172^{\circ}$ after superhydrophobic functionalization by application of covalently bonded fluorinated organosilane groups.
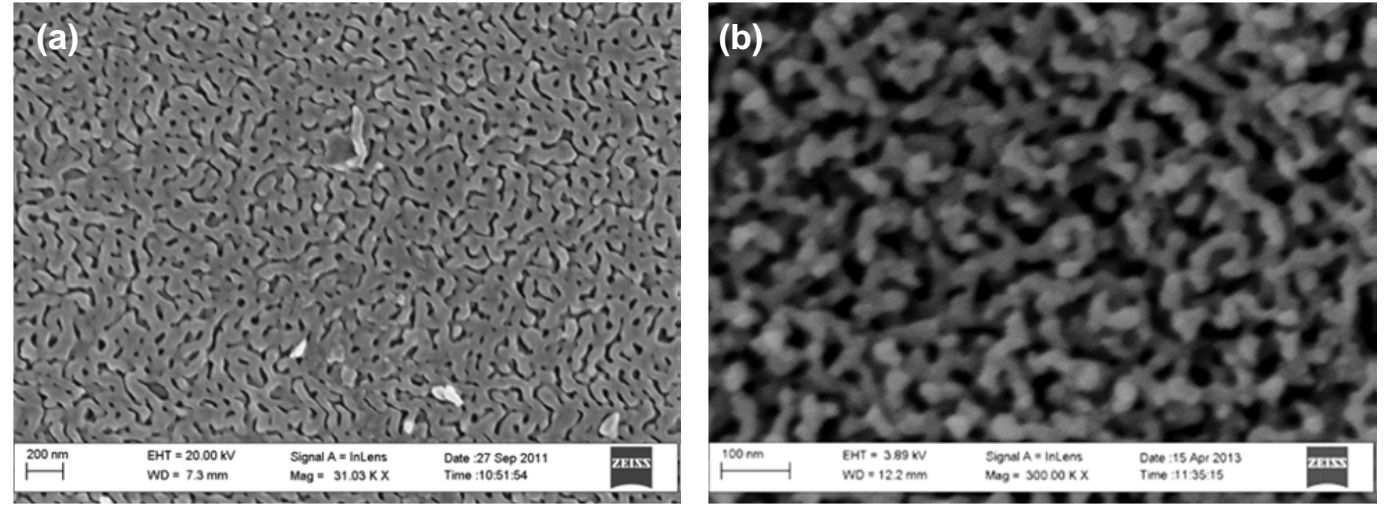

Fig. 9. SEM images illustrating (a) formation of spinodal two-phase separated structure after the heat treatment and (b) transformation of part (a) surface into a reticulated network nanostructure after the differential etching process.

With an approximate pore size of 10 to $20 \mathrm{~nm}$, the nanostructured silica film surface displayed in Fig. 9(b) is inherently hydrophilic and demonstrates structural superhydrophilic behavior, such that water rapidly spreads and wets the film by the capillary action. Such surfaces promote condensation to form a continuous film that spontaneously fills the nanopores, providing strong antifogging characteristics [see Figs. 10(a) and (b)]. After functionalization with organosilane molecules, the surface exhibits superhydrophobic behavior, with a static water droplet CA, $\theta$, as large as $172^{\circ}$ [(see Fig. 8(b)]. A more representative value of static CA over the entire surface is $\sim 162.7^{\circ}$, and average advancing, $\theta_{\mathrm{adv}}$, and receding $\theta_{\text {rec }}$, contact angles are $\sim 166.5^{\circ}$ and $\sim 163.6^{\circ}$, respectively. The millimetric water droplets (dyed blue) that are randomly placed on the superhydrophobic film [as shown in Fig. 8(a)] form a nearly spherical shape and easily roll off the surface at a $<5^{\circ}$ tilt angle as a result of the small CA hysteresis of $\sim 2.9^{\circ}$ (i.e., the difference between $\theta_{\mathrm{adv}}$ and $\theta_{\mathrm{rec}}$ ). Note that CA hysteresis arises from the chemical and topographical heterogeneity of the surface. Consequently, the combination of high static CA and low CA hysteresis leads to surfaces with self-cleaning ability [35]. Water droplets on such surfaces do not penetrate into the valleys (i.e., nanopores of the silica matrix in our case); rather, they are suspended on the surface prominences. Besides remarkable water-repellent properties, these bicontinuous silica films also demonstrate excellent transparency over a wide range of wavelengths $(\lambda)$ and incident angles. Figure 11a compares wavelength-dependent transmittance of single-side coated and uncoated fused-quartz substrates at near normal incidence. Compared to the underlying reference template, the 
superhydrophobic sample shows enhanced transmittance for wavelengths ranging from mid infrared down to ultraviolet (UV) (3000 $\mathrm{nm} \geq \lambda \geq 200 \mathrm{~nm}$ ), remaining above 94\% in the visible regime. In Fig. 8a, the clear visualization of the optical bench finish and mounting hole threads beneath the substrate further substantiates the high transparency of the nanotextured silica films. However, the measurements also showed a substantial decrease in transmittance at shorter wavelengths [see inset in Fig. 11(a)] due to increased scattering by surface features $(\leq 100 \mathrm{~nm})$, signifying a UV-blocking functionality.
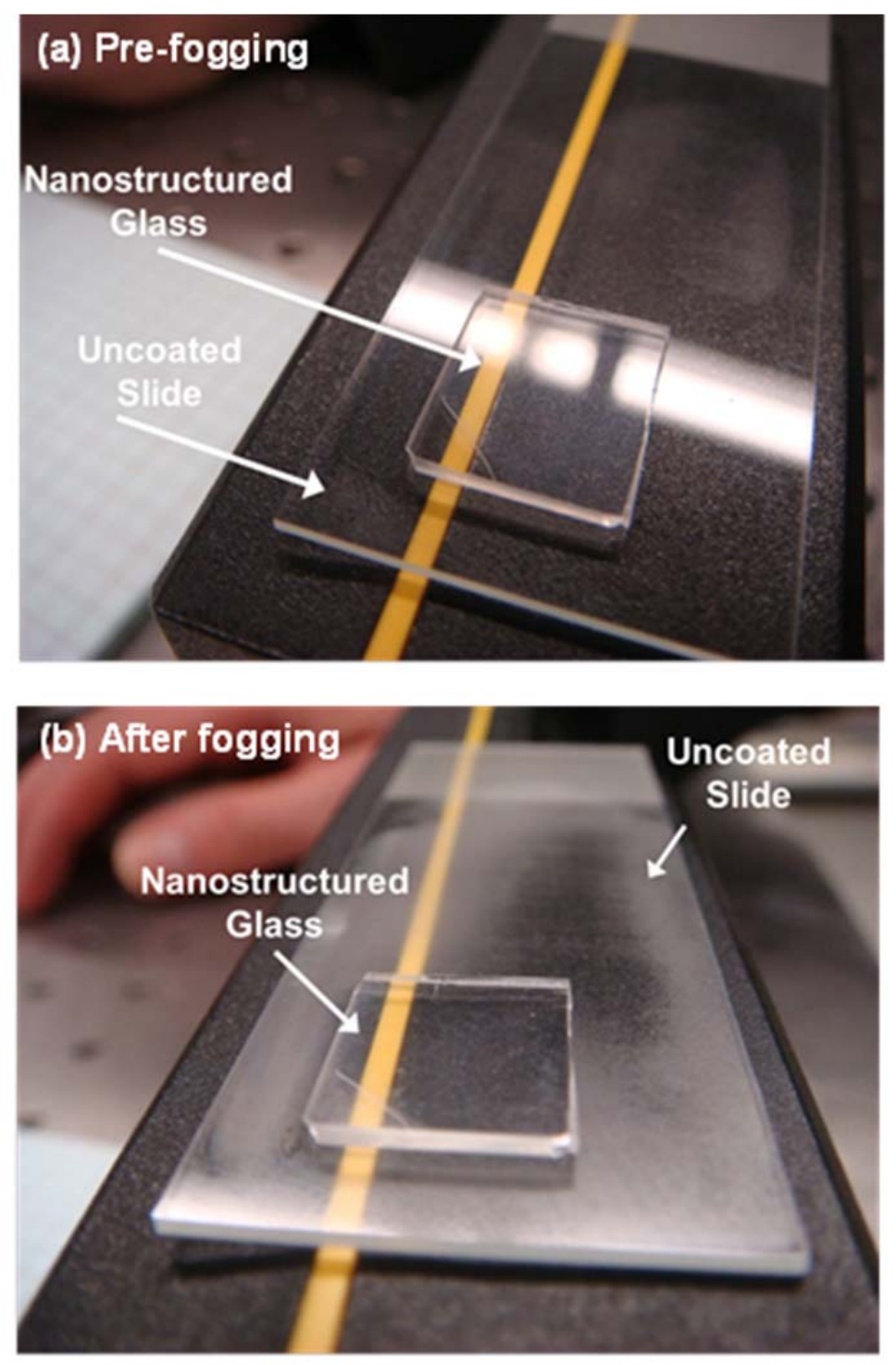

Fig. 10. Photographs of a nanostructured thin-film-coated sample placed on an uncoated microscope slide (a) before and (b) after being subjected to fogging. Optical clarity of the sample after fogging qualitatively confirms the inherent antifogging characteristics of the nanotextured surface.

Omnidirectional characteristics of these coatings were investigated by direct transmittance measurements between $3000 \mathrm{~nm} \geq \lambda \geq 200 \mathrm{~nm}$ and for angles of incidence varying from $0^{\circ}$ to $80^{\circ}$ with $10^{\circ}$ increments. For both coated and uncoated samples, data are presented as a hemispherical polar representation in Fig. 11(b) at two specific wavelengths covering the visible $(\lambda=600 \mathrm{~nm})$ and $U V(\lambda=200 \mathrm{~nm})$ region. Compared to the flat uncoated counterpart, the nanostructured surface enables slightly better transmittance at $\lambda=600 \mathrm{~nm}$ (also at other longer wavelengths; data not shown here) for all angles of 
incidence, demonstrating the omnidirectional nature of the nanotextured silica films across a broad light spectrum. Measurements also verified omnidirectional UV-blocking characteristics of the coatings on the fused-quartz platforms. Protection against UV light is needed due to its harmful biological effects or to degradation of various organic and polymeric compounds, which would be important for various USMC devices employing polymeric binders or components.

a)

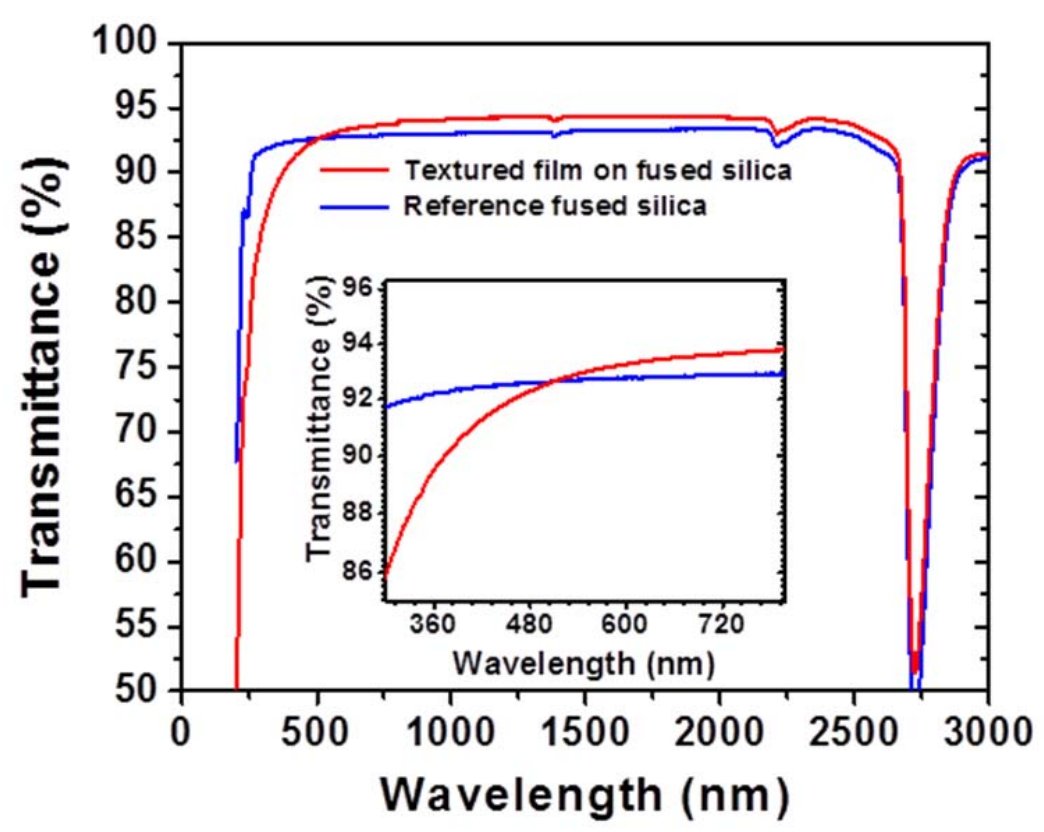

b)

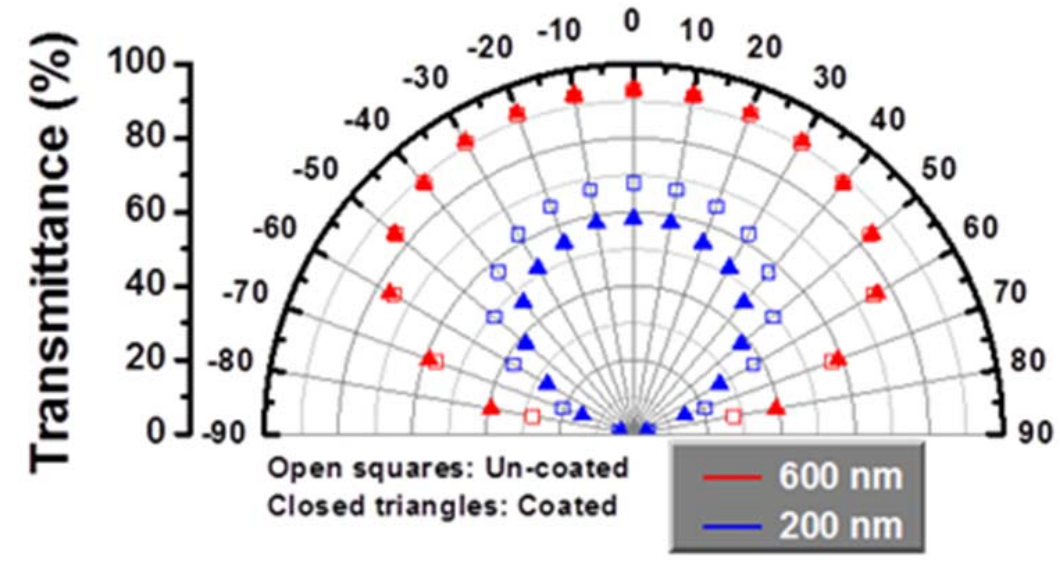

Fig. 11. (a) Optical transmittance spectra obtained through a nanostructured film surface. For comparison, a spectrum of the uncoated fused-quartz reference is also included. Inset shows the transmittance in the UV regime. Enhanced broadband transmissivity and UV blocking performance of the coating are apparent. (b) Angulardependent transmittance of the same samples as presented in part (a), for discrete representative wavelengths of $600 \mathrm{~nm}$ and $200 \mathrm{~nm}$.

In addition to UV blocking functionality, the nanostructured silica films need to be mechanical and structurally stable for their effective utilization in the field. Therefore, mechanical, thermal, and 
environmental robustness of the coatings for possible real-world applications (e.g., rifle scopes and other optical sensors) were assessed by performing tests of abrasion resistance, nanoindentation fracture toughness, and heat tolerance. Two complementary tests were conducted to qualify the films for abrasion resistance. First, sharp and rugged-edged $\mathrm{Al}_{2} \mathrm{O}_{3}$ particles (see Fig. 12) were impacted on a superhydrophobic surface from a height of $\sim 35 \mathrm{~cm}$. The test was based on previously reported methods [36], but the current testing used a much more aggressive abrasive, $\mathrm{Al}_{2} \mathrm{O}_{3}$ versus $\mathrm{SiO}_{2}$, and approximately three times more material (see Sect 3.3.3). After the test, the surface remained superhydrophobic, and the values of average static water droplet CA and roll-off angle were virtually unchanged $\left(\sim 156.4^{\circ}\right.$ and $\sim 4^{\circ}$, respectively). In the subsequent test, outdoor dust storm conditions were simulated. An apparatus made in-house and the procedure illustrated in Fig. 13(a) were used to blast the same superhydrophobic sample with $\mathrm{Al}_{2} \mathrm{O}_{3}$ particles at a velocity $(v)$ of $40 \mathrm{~km} \mathrm{~h}^{-1}$ for $15 \mathrm{~min}$. Even after that aggressive test, superhydrophobic properties were maintained. Water droplets bounced and easily rolled off the tested surface; before-test and after-test CA and roll-off angles were similar ( $\sim 155^{\circ}$ and $\sim 4^{\circ}$, respectively). Figure 13(b) displays the appearance of the sample surface after the test. The narrow region where the water was applied and repelled is well cleaned, and the settlement of the $\mathrm{Al}_{2} \mathrm{O}_{3}$ dust on the rest of the surface is clearly apparent from the photograph, illustrating the self-cleaning property of the coating. Like many nonwetting biological systems (e.g., lotus leaves and water strider legs), such artificially created superhydrophobic surfaces can be effectively cleaned by the water droplets because the adhesion between the contaminant particles and the superhydrophobic surface is much less than the adhesion between the contaminant particles and the water droplets. For military equipment, self-cleaning ability will deliver much needed safety and functionality for soldiers, and it will also mitigate biofouling of optical windows exposed to highly humid conditions.

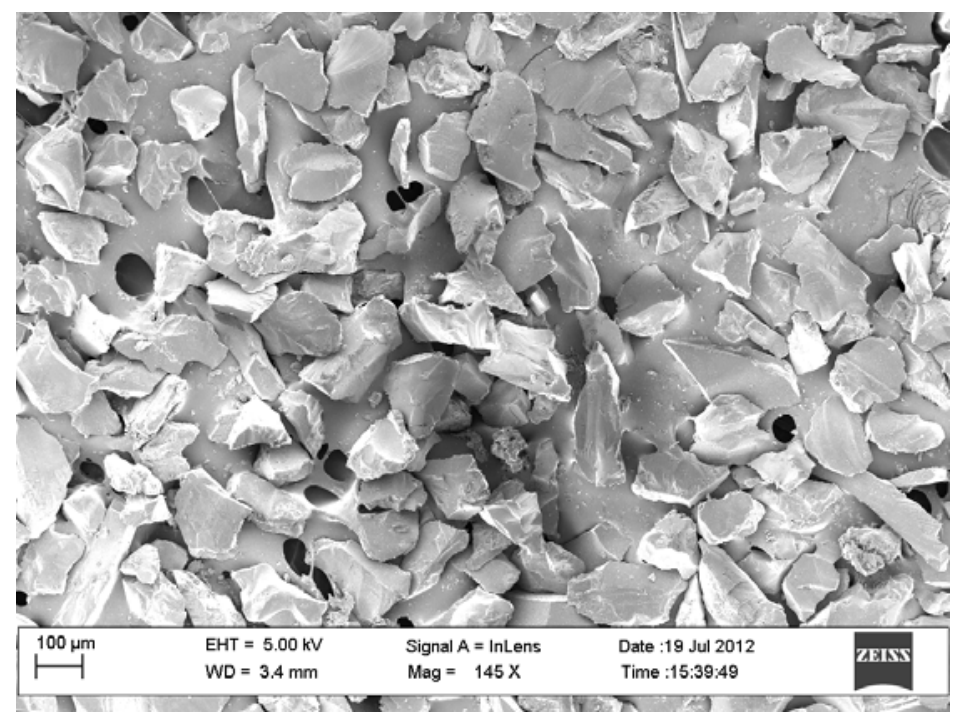

Fig. 12. Scanning electron microscopy image of the $\mathrm{Al}_{2} \mathrm{O}_{3}$ particles used in the abrasion tests. 
(a)

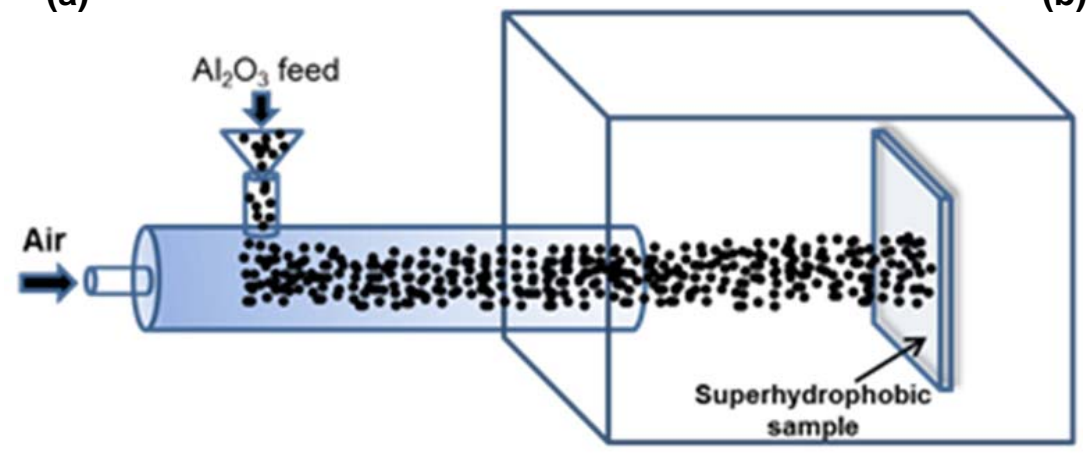

(b)

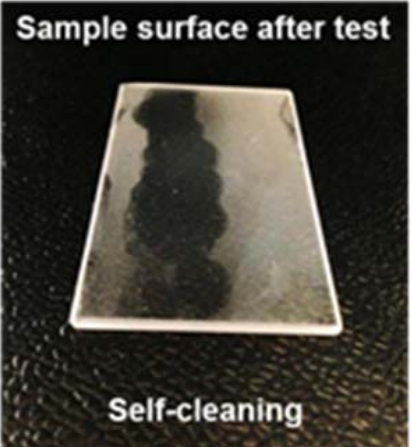

Fig. 13. (a) Schematic of the setup used to evaluate mechanical stability and durability of the superhydrophobic silica film surface under simulated dust-storm conditions (highly abrasive $\mathrm{Al}_{2} \mathrm{O}_{3}$ particles were used). (b) Appearance of the sample surface after the test.

The retention of superhydrophobic attributes after the second wear test is not surprising, considering the nanostructured nature of the coating throughout the entire film thickness. That is, even if there was damage to the top surface, the film matrix below the surface is protected and possesses similar microstructure, ensuring preservation of superhydrophobic properties. To quantify the impact energy $\left(E_{\mathrm{i}}\right)$ of $\mathrm{Al}_{2} \mathrm{O}_{3}$ onto the surface, it was assumed that the particles are rectangular in shape with an average length $(l)$, width $(w)$, and height $(h)$ of $200 \mu \mathrm{m}, 100 \mu \mathrm{m}$, and $30 \mu \mathrm{m}$, respectively. This yields an estimated value of $E_{\mathrm{i}}=1 / 2 m v^{2}=1.46 \times 10^{-7} \mathrm{~J}$, where $m=l w h \mathrm{~h}$ is the mass and $\rho=3.95 \mathrm{~g} \mathrm{~cm}^{-3}$ is the density of the $\mathrm{Al}_{2} \mathrm{O}_{3}$. For comparison with the softer and smaller (50 $\mu \mathrm{m}$ in diameter) $\mathrm{SiO}_{2}$ particles that would more accurately characterize real wind-storm conditions, the estimated $\mathrm{SiO}_{2}$ particle impact energy of $1.07 \times 10^{-8} \mathrm{~J}$ is substantially lower, signifying that the nanoscale features on the silica surface should withstand even higher windstorm velocities.

Following the abrasion tests, nanoindentation measurements were conducted to evaluate resistance to cracking or fracture. Films of approximately $1 \mu \mathrm{m}$ thickness were fabricated on fused-quartz templates, and a $100 \mathrm{~nm}$ cube-corner indenter was used for measurements on both as-deposited dense films and on the final etched product. The method, which is based on the radial cracking that occurs when brittle materials are deformed by a sharp indenter, yields an estimation of indentation fracture toughness from measurements of crack length and maximum indentation load. Atomic force microscopy images shown in Fig. 14 illustrate the surface morphologies of a sputter-deposited film, a fully processed film, and the underlying fused-quartz substrate before and after the indentations. After application of the equipment maximum load of $10,500 \mu \mathrm{N}$, where the tip penetrated approximately $65 \%$ to $80 \%$ into the film thickness, no evidence of cracks emanating from the corners of the indented impressions was observed. Hence the indentation fracture resistance could not be quantified for the thin film materials at the maximum load of the testing equipment. Nevertheless, this result indicates that the sputter-deposited coatings, whether dense or porous, are strong and crack resistant. Compared to the underlying substrate, the dense film (before processing) releases the built-up energy in the form of material pileup on the edges of the indentation; this behavior is most likely due to the heavily strained nature of the as-deposited film, with only small reserve for further work-hardening [37]. The fact that annealed and differentially etched films do not exhibit such pileup suggests that the fully processed films accommodate strain or material movement more easily owing to their porous microstructure. Thermal stability of the coatings must also be ensured. To determine the thermal tolerance, another superhydrophobic sample (average $\mathrm{CA} \sim 156^{\circ} \mathrm{C}$ ) was iteratively annealed for $30 \mathrm{~min}$ in air to successive temperatures in the range from $100^{\circ} \mathrm{C}$ to $600^{\circ} \mathrm{C}$. After each thermal exposure, the static CA at room temperature was found to remain constant for heat treatments up to at least $500^{\circ} \mathrm{C}$ [Fig. 15(a)], indicating excellent temperature stability of the atomically bonded nanotextured coatings. In contrast, treatment temperatures above $500^{\circ} \mathrm{C}$ resulted in a total loss of 
superhydrophobic performance, with CA $\left(\sim 17^{\circ}\right)$ decreasing to those values obtained on uncoated flat glass surfaces [Fig 15(b)]. Degradation from such excessive heat treatment was attributed to burn-off of the chemically hydrophobic fluorocarbon layer.
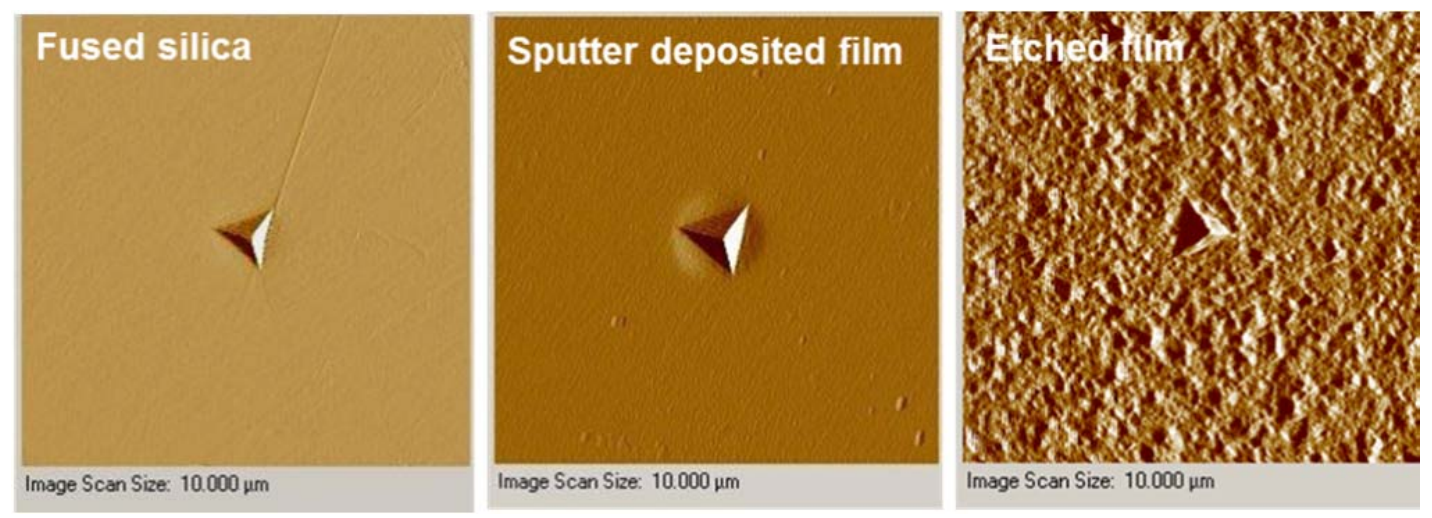

Fig. 14. Atomic force microscopy images of cube-corner indentations obtained on an as-deposited and a nanotextured glass thin film. Data for the underlying fused-quartz substrate are included for comparison. No cracks are observed on any sample, aside from a scratch on the fused-quartz surface due to handling.

(a)
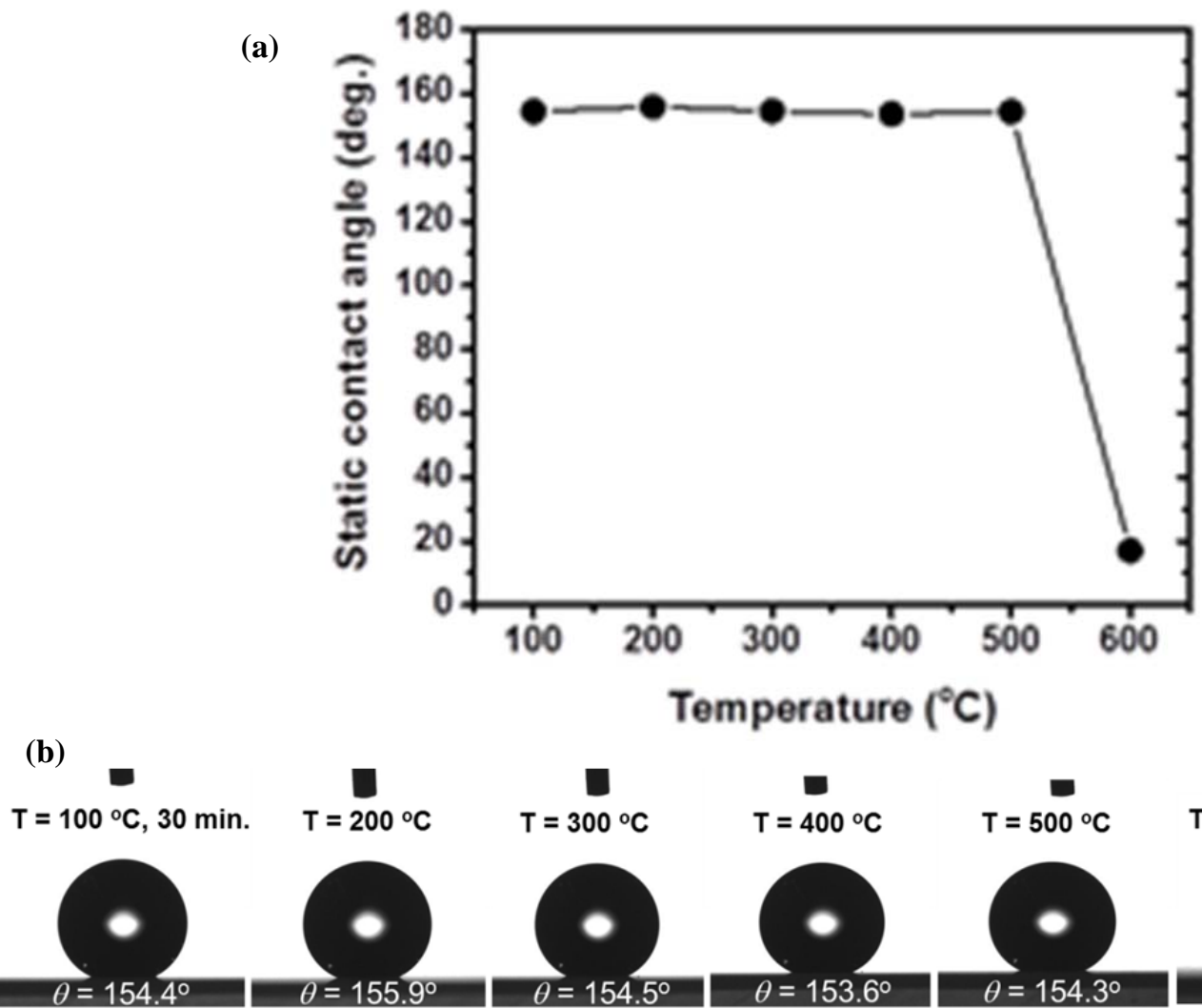

$T=600^{\circ} \mathrm{C}$

Fig. 15. (a) Static contact angles of water droplets on a nanostructured superhydrophobic thin film, after successive $30 \mathrm{~min}$ exposures to the indicated temperatures. The results demonstrate excellent thermal stability up to $500^{\circ} \mathrm{C}$. (b) Profile of the water droplets $(\sim 3 \mu \mathrm{L})$ at successive temperatures. 


\section{CONCLUSIONS}

The first reported atomically bonded, optically transparent, and durable superhydrophobic coatings on glass platforms were applied to at ORNL by means of the various combinations and modifications described in this report. The nanotextured films exhibit superior superhydrophobicity following a simple but durable, modification in surface chemistry, yielding water droplet contact angles as high as $172^{\circ}$. Moreover, the nanostructure of the coatings provides increased light scattering in the UV regime and reduced reflectivity (i.e., enhanced transmission) over a broad range of the visible spectrum. In addition to these functionalities, it was shown that the present coatings exhibit superior mechanical resistance to abrasion and that are thermally stable to temperatures approaching $500^{\circ} \mathrm{C}$. The approach developed at ORNL offers potential tunability of salient functionalities for specific performance requirements and for applicability to a wide variety of glass platforms. Because the coating and substrate are inherently similar and intimately bonded materials, the resulting entity is essentially monolithic, representing a conceptually fundamental basis to be developed for leading-edge optical-quality products.

This development is part of an overall larger corrosion-mitigation program at ORNL and aligns well with the strategic focus of the USMC CPAC program. These techniques have the potential to generate thin films with very high levels of mechanical, thermal, and environmental stability while relying on standard commercial manufacturing processes that are inherently scalable and cost-effective. The intent of this effort is to significantly improve surface functionality of the optical windows (e.g., employed in periscopes, rifle scopes and vehicle windshields) by developing a well-bonded superhydrophobic thinfilm coating that is virtually indistinguishable from the underlying optically transparent substrate. The ability to produce atomically bonded, transparent superhydrophobic coatings on various clear surfaces will facilitate the manufacturing of cutting-edge visibility-control products with exceptional mechanical and environmental durability. The robustness of the coating combined with its advanced functionality has the potential to have a huge effect on USMC assets as well as the assets managed by the rest of DOD. The technology that was developed within the research scope will significantly enhance the performance of current and future combat vehicles and equipment; enhance reliability, visibility, and performance; deliver much needed safety and increased readiness; and provide a strategic advantage for warfighters in the field.

\section{REFERENCES}

1. P. Roach, N. J. Shirtcliffe and M. I. Newton 2010 Soft Matter 4224.

2. X. Zhang, F. Shi, J. Niu, Y. Jiang and Z. Wang 2008 J. Mater. Chem. 18621.

3. X.J. Feng and L. Jiang 2006 Adv. Mater. 183063.

4. X. Yao, Y. Song, L. Jiang 2011 Adv. Mater. 23719.

5. W. L. Min, B. Jiang, P. Jiang 2008 Adv. Mater. 203914.

6. K-C. Park, H. J. Choi, C-H. Chang, R. E. Cohen, G. H. McKinley and G. Barbastathis 2012 ACS Nano 63789.

7. Y. Xu, W. H. Fan, Z. H. Li, D. Wu and Y. H. Sun 2003 Appl. Opt. 42108.

8. J. Zhu, C. M. Hsu, Z. F. Yu, S. H. Fan and Y. Cui 2010 Nano Lett. 101979.

9. G. Gu, H. Dang, Z. Zhang and Z. Wu 2006 Appl. Phys. A 83131.

10. X. Zhang, H. Kono, Z. Liu, S. Nishimoto, D. A. Tryk, T. Murakami, H. Sakai, M. Abe and A. Fujishima 2007 Chem. Comm. 464949. 
11. A. Nakajima, A. Fujishima, K. Hashimoto and T. Watanabe 1999 Adv. Mater. 111365.

12. T. Verho, C. Bower, P. Andrew, S. Franssila, O. Ikkala and R. H. A. Ras 2011 Adv. Mater. 23673.

13. T. Yanagisawa, A. Nakajima, M. Sakai, Y. Kameshima and K. Okada 2009 Mater. Sci. Eng., B 161 36.

14. X. Deng, L. Mammen, Y. Zhao, P. Lellig, K. Müllen, C. Li, H-J. Butt and D. Vollmer 2011 Adv. Mater. 232962.

15. B. Bhushan, Y. C. Jung and K. Koch 2009 Phil. Trans. R. Soc. A 3671631.

16. M. Nosonovsky and B. Bhushan 2008 J. Phys.: Condens. Matter. 20225009.

17. H. Y. Erbil, A. L. Demirel, Y. Avci and O. Mert 2003 Science 2991377.

18. J. Fresnais, J.P. Chapel and F. Poncin-Epaillard 2006 Surf. Coat. Technol. 2005296.

19. K. Teshima, H. Sugimura, Y. Inoue, O. Takai and A. Takano 2005 Appl. Surf. Sci. 244619.

20. P. A. Levkin, F. Svec and J. M. J. Fréchet 2009 Adv. Funct. Mater. 191.

21. K. Tadanaga, N. Katata and T. Minami 1997 J. Am. Ceram. Soc. 801040.

22. H.M. Shang, Y. Wang, K. Takahashi and G. Z. Cao 2005 J. Mater. Sci. 403587.

23. H. Ogihara, J. Xie, J. Okagaki and T. Saji 2012 Langmuir 284605.

24. S. A. Mahadik, D. B. Mahadik, M. S. Kavale, V. G. Parale, P. B. Wagh, H. C. Barshilia, S. C. Gupta, N. D. Hegde and A. V. Rao 2012 J. Sol-Gel Sci. Technol. 63580.

25. Y. L. Wu, G. H. Tan, X. T. Zeng, T. H. Li and Z. Chen 2006 J. Sol-Gel Sci. Technol. 3885.

26. Y. Gao, Y. Huang, S. Feng, G. Gu and F-L. Qing 2010 J. Mater. Sci. 45460.

27. X. Y. Ling, I. Y. Phang, G. J. Vancso, J. Huskens and D. N. Reinhoudt 2009 Langmuir 253260.

28. C. Sun, L. Q. Ge and Z. Z. Gu 2007 Thin Solid Films 5154686.

29. P. S. Tsai, Y. M. Yang and Y. L. Lee 2006 Langmuir 225660.

30. Y. Xiu, Y. Liu, D.W. Hess and C.P. Wong 2010 Nanotechnology 211.

31. I.S. Bayer, A. Brown, A. Steele and E. Loth 2009 Appl. Phys. Express 25003.

32. Y. L. Wu, Z. Chen and X. T. Zeng, Appl. Surf. Sci. 2546952.

33. K. Makita, Y. Akamatsu, S. Yamazaki, Y. Kai and Y. Abe, J. Ceram. Soc. Jpn. 1051012.

34. Y. Wang, D. Raabe, C. Klüber and F. Roters 2004 Acta Materialia 52222.

35. B. Bhushan and Y. C. Jung 2008 J. Phys. Condens. Matter. 20225010.

36. X. Deng, L. Mammem, Y.F. Zhao, P. Lellig, K. Müllen, C. Li, H-J. Butt and D. Vollmer 2010 Adv. Mater. 232962.

37. Y. Wang, D. Raabe, C. Klüber and F. Roters 2004 Acta Materialia 52222. 